\title{
Adhesion of Candida albicans and Candida dubliniensis to acrylic and hydroxyapatite
}

\author{
Mariana Henriques, Joana Azeredo, Rosário Oliveira* \\ Centro de Engenharia Biológica-CEB, Universidade do Minho, Braga, Portugal
}

Received 30 June 2003; received in revised form 8 August 2003; accepted 14 October 2003

\begin{abstract}
The aim of this work was to compare the ability of strains of Candida albicans and Candida dubliniensis to adhere to acrylic and hydroxyapatite (HAP). In order to interpret the adhesion results, the surface properties of cells and materials were determined. Surface tension components (polar and apolar) and hydrophobicity were calculated through contact angle measurement and the elemental composition was determined by X-ray photoelectron spectroscopy (XPS). The results showed no significant differences in the number of adhered cells of both species to acrylic and hydroxyapatite. This was corroborated by the similarities in their surface properties and elemental composition. For both species, the adhesion to acrylic increased in the presence of artificial saliva due to the increase in the electron-donor capacity of this material. In the absence of artificial saliva, the number of adhered cells to HAP was greater than to acrylic, on account of the higher number of electron-donor groups of HAP. Hydrophobicity played a minor role in the adhesion process of both candidal species. Conversely, Lewis acid-base interactions seamed to govern this phenomenon.
\end{abstract}

(c) 2003 Elsevier B.V. All rights reserved.

Keywords: Candida albicans; Candida dubliniensis; Adhesion; Surface properties

\section{Introduction}

Candida albicans is a commensal pathogen that lives on the skin and mucosal surfaces of the genital and intestinal tracts as well as the oral cavity. [1-3]. This species is one of the most common responsible for nosocomial infections. Recently, Sullivan et al. [4] described a new species of Candida, C. dubliniensis, isolated from the oral cavity of HIV patients, that is phenotypically and genotypically close to Candida albicans. Evidence of the inducibility of a stable fluconazole resistance in vitro in $C$. dubliniensis strains may indicate that it is an emerging pathogen for immunocompromised patients receiving long-term fluconazole prophylaxis [5]. Candida dubliniensis is the non-Candida albicans species most capable of adhesion to epithelial cells, which may indicate that this species is particularly adapted to colonise the oral cavity [6].

\footnotetext{
* Corresponding author. Tel.: +351-253-604409; fax: +351-253-678986.

E-mail address: roliveira@deb.uminho.pt (R. Oliveira).
}

Since the oral cavity is a continuous-flow environment, yeast cells are washed out by saliva and swallowed unless they adhere and replicate. Moreover, growth conditions in the oral cavity are so poor that cells have to adhere to be maintained [2]. So, an essential pre-requisite for the successful colonisation of host tissues by these micro-organisms is the ability to adhere to superficial epithelial cells, or to a closely associated surface [7]. Denture stomatitis is common among denture wearers. Numerous yeasts are commonly found on the palatal surface of the denture [8] and this supports the theory that the upper denture acts as a reservoir for infection. Thus, it is of major importance to study the adhesion of Candida spp. to oral surfaces, including prosthetic devices (polymers) and teeth enamel, mainly composed of calcium phosphate, usually simulated, in vitro, by hydroxyapatite. Although the adhesion of Candida albicans to oral surfaces has been intensively studied there are no reports, to the authors' knowledge, of the adhesion of Candida dubliniensis to oral devices. So, this work aims at comparing the adhesion ability of these two different Candida species to acrylic and HAP. 


\section{Materials and methods}

\subsection{Yeast growing conditions}

Two different strains of Candida albicans and Candida dubliniensis were used in this work. Candida albicans $12 \mathrm{~A}$ and Candida albicans 46B are clinical isolates, kindly provided by the Department of Biology of the University of Minho. Candida dubliniensis CBS 7987 and Candida dubliniensis CBS 7988 were obtained from Centraalbureau voor Schimmelcultures (CBS). Both species were stored in Sabouraud dextrose agar at $5^{\circ} \mathrm{C}$ and sub-cultured every month. For each assay, the yeast cells were sub-cultured in Sabouraud dextrose agar for $24 \mathrm{~h}$ and then grown in Sabouraud dextrose broth for $18 \mathrm{~h}$, at $37^{\circ} \mathrm{C}$ under agitation, until stationary phase. Cells were harvested by centrifugation $(5000 \mathrm{rpm}$, for $10 \mathrm{~min}$ ) and washed twice with ultrapure water. The cells were resuspended in a certain volume of water or artificial saliva necessary to achieve the concentration needed for each assay, after being enumerated in a "Neubauer" chamber.

\subsection{Artificial saliva preparation}

Artificial saliva was prepared according to Gal et al. [9] with the following composition in $\mathrm{mg} / \mathrm{l}$ : $125.6 \mathrm{NaCl}, 963.9$ $\mathrm{KCl}, 189.2 \mathrm{KSCN}, 654.5 \mathrm{KH}_{2} \mathrm{PO}_{4}, 200.0$ Urea, 763.2 $\mathrm{Na}_{2} \mathrm{SO}_{4} \cdot 10 \mathrm{H}_{2} \mathrm{O}, 178.0 \mathrm{NH}_{4} \mathrm{Cl}, 227.8 \mathrm{CaCl}_{2} \cdot 2 \mathrm{H}_{2} \mathrm{O}$ and $630.8 \mathrm{NaHCO}_{3}$. The $\mathrm{pH}$ was adjusted to 6.8 , by bubbling carbon dioxide.

\subsection{Adhesion surfaces}

Two substrata were used in the adhesion assays, hydroxyapatite (batch P120, Plasma Biotal; UK) and selfpolymerising acrylic (Vertex, Self Curing, Dentimex BV, The Netherlands).

The hydroxyapatite discs were prepared with hydroxyapatite powder as reported by Lopes et al. [10]. The HAP powder was uniaxially pressed at $288 \mathrm{MPa}$ in steel dishes to produce $14 \mathrm{~mm}$ diameter and $2 \mathrm{~mm}$ thickness discs using $4 \mathrm{~g}$ of powder. Discs were then placed on an alumina tile and fired to $1300{ }^{\circ} \mathrm{C}$ at a ramp rate of $4{ }^{\circ} \mathrm{C} / \mathrm{min}$. The set temperature was maintained for $1 \mathrm{~h}$, followed by natural cooling inside the furnace. The discs were mechanically polished by several sandpapers with decreasing granulometry to a final $1 \mu \mathrm{m}$ finish.

The acrylic coupons were prepared as described by Samaranayake and MacFarlane [7]. Briefly, $1.5 \mathrm{~g}$ of self-polymerising acrylic powder was mixed with $1 \mathrm{ml}$ of monomer liquid and after mixing the solution was poured onto a surface covered with aluminium foil paper. After $45 \mathrm{~s}$ another surface was placed on top of the polymerising mixture. The acrylic sheet, polymerised during $30 \mathrm{~min}$, was cut into $8 \mathrm{~mm} \times 8 \mathrm{~mm} \times 2 \mathrm{~mm}$.
Coupons of both materials, after being washed with water, ethanol and ultrapure sterile water, were immersed in sterile water or sterile artificial saliva, for $24 \mathrm{~h}$ at room temperature, and dried at $37^{\circ} \mathrm{C}$ for $24 \mathrm{~h}$, before adhesion and surface properties studies (X-ray photoelectron spectroscopy (XPS) and contact angle measurement).

\subsection{Surface properties}

\subsubsection{Contact angle measurement}

Cell lawns were prepared according to Henriques et al. [11]. Briefly, a solution of $20 \mathrm{~g} / \mathrm{l}$ of agar, and $10 \%(\mathrm{v} / \mathrm{v})$ of glycerol was cast onto a microscope slide $(75 \mathrm{~mm} \times 25 \mathrm{~mm})$. An aliquot of $2 \mathrm{ml}$ of $10^{9}$ cells $/ \mathrm{ml}$ (prepared in water or artificial saliva) was spread over the solidified agar layer, in order to cover the entire surface. This layer was let to dry at $37^{\circ} \mathrm{C}$ (for $10-15 \mathrm{~h}$ ), and two more layers were added, with the same drying period between them.

Contact angles were measured by the sessile drop technique on the cell lawns and on the materials prepared as indicated in 2.3, using a contact angle measurements apparatus (model OCA 15 PLUS, DATAPHYSICS). The measurements were performed at room temperature, using three different liquids: water, formamide and 1-bromonaphtalene. Each assay was performed in triplicate and at least 10 contact angles, per sample, were measured.

\subsubsection{X-ray photoelectron spectroscopy}

A volume of $200 \mathrm{ml}$ of an aqueous cell suspension $\left(10^{9}\right.$ cells $\left./ \mathrm{ml}\right)$ was vacuum filtered through a nitro-cellulose membrane of $45 \mu \mathrm{m}$. The membrane, completely covered with cells, was immediately frozen with liquid nitrogen and then stored at $-80^{\circ} \mathrm{C}$ until the subsequent step of lyophilization. Freeze drying was performed at $10 \mathrm{~Pa}$, overnight. The samples were placed in a dessicator, at room temperature and immediately analysed by XPS. The XPS analysis was performed using an apparatus ESCALAB 200A, with a VG5250 software and data analysis. The spectrometer used monochromatized $\mathrm{Mg} \mathrm{K} \alpha \mathrm{X}$-ray radiation $(15,000 \mathrm{eV})$. The constant pass energy of the analyser was $20 \mathrm{eV}$ and it was calibrated with reference to $\mathrm{Ag} 3 \mathrm{~d}_{5 / 2}(368.27 \mathrm{eV})$. The pressure during analysis was under $1 \times 10^{-6} \mathrm{~Pa}$. The spectra, for yeast cells, were recorded following the sequence $C$ $1 \mathrm{~s}, \mathrm{O} 1 \mathrm{~s}, \mathrm{~N} 1 \mathrm{~s}, \mathrm{P} 2 \mathrm{p}$. In the case of HAP and acrylic, the spectra sequence was: C 1s, O 1s, N 1s, P 2p, Si 2p, Na 1s, $\mathrm{Ca} 2 \mathrm{p}\left(2 \mathrm{p}^{3}+2 \mathrm{p}^{1}\right), \mathrm{K} 2 \mathrm{p}\left(2 \mathrm{p}^{3}+2 \mathrm{p}^{1}\right)$.

\subsubsection{Zeta potential}

Cells were diluted in water and artificial saliva to an absorbance of approximately 0.1 (measured at $600 \mathrm{~nm}$ ). The zeta potential was determined by electrophoretic mobility by means of a Zeta-Meter (Zeta-Meter System, 3.0+).

\subsubsection{Roughness}

The surface roughness of acrylic and HAP was determined using a roughness tester (Surftest SV 512). 
Measurements were done in both longitudinal and transversal directions.

\subsection{Adhesion assays}

Coupons of acrylic and HAP, prepared as indicated in 2.3 , were inserted in a 24 -well plate $(15 \mathrm{~mm}$ diameter each well) and $2 \mathrm{ml}$ of a cell suspension of $10^{7}$ cells $/ \mathrm{ml}$, prepared with water or artificial saliva, were added to each well. After $1 \mathrm{~h}$ of incubation $\left(100 \mathrm{rpm}\right.$, at $\left.37^{\circ} \mathrm{C}\right)$ each well was washed twice with ultrapure water, by pipeting carefully only the liquid above the coupon. After the last washing, the liquid was completely removed. The coupons were then stained with SYTO-13 (Molecular Probes) for $5 \mathrm{~min}$, and observed under epifluorescence microscopy (450-490 nm). Twenty-five fields per sample were randomly captured by a video camera connected to the microscope and grabbed by a computer. An image analysis system (SigmaScan Pro 5, SPSS) was used to quantify the adhered yeast cells. Each experiment was repeated six times.

\subsection{Statistical analysis}

The resulting data were analysed using SPSS (Statistical Package for the Social Sciences). Two-way ANOVA was used to perform multiple analysis of the interaction between all factors. One-way ANOVA with Bonferroni test was used to compare the number of adhered cells of the four strains. All tests were performed with a confidence level of $95 \%$.

\section{Results}

\subsection{Adhesion assays}

The number of cells of Candida albicans and Candida dubliniensis adhered to each type of material immersed in water or in artificial saliva is presented in Table 1.

The two-way ANOVA analysis of the results (Table 1) revealed that adhesion is mainly influenced by the type of material (HAP and acrylic) and the liquid medium where adhesion occurred (artificial saliva or water) $(P=0.000$ for both cases). For each type of material, no statistical differ- ence was found between the number of adhered cells of the strains studied $(P=0.655)$.

To better understand the influence of each factor in the process of adhesion, a statistical analysis (one-way ANOVA) was performed with each variable, separately. When water was used as the adhesion medium, the differences in the number of cells adhered to HAP and to acrylic were significantly different (values of $P$ were $0.001,0.014,0.000$ and 0.008 for each strain, respectively, as ordered in the Table 1), with a higher number adhered to HAP than to acrylic. In the case of artificial saliva, these differences were not significant (values of $P$ for the strains $C$. albicans 12A, C. albicans 46B and $C$. dubliniensis 7988 were $0.277,0.107$ and 0.091 , respectively), except in the case of $C$. dubliniensis 7987 ( $P=$ 0.018 ). Considering the adhesion to acrylic, the number of cells attached in the presence of artificial saliva was significantly greater than in the presence of water $(P=0.003$ for $C$. albicans $12 \mathrm{~A}$ and $P=0.001$ for the other strains). For HAP, the results of the assays performed in water and artificial saliva were not significantly different $(P$ equal to 0.225, 0.308 and 0.086 for strains $C$. albicans 12A, C. albicans 46B and $C$. dubliniensis 7987, respectively) except in the case of $C$. dubliniensis 7988 (where $P=0.022$ ).

\subsection{Cell surface properties}

The results obtained by XPS analysis on the $\mathrm{C}, \mathrm{O}, \mathrm{N}$ and $\mathrm{P}$ composition of the yeast cells surfaces are expressed in terms of ratios and are presented in Fig. 1. The ratios of cell wall components are similar for all the strains studied.

The contact angles formed by the three liquids (water, formamide and 1-bromonaphethalene) on cell lawns of all strains, pre-contacted with water or artificial saliva, are presented in Table 2. The values indicate that all strains have similar interactions with each of the three liquids tested. The water contact angle can give an indication of the surface hydrophobicity. According to van Oss and Giese [12] a water contact angle lower than $50^{\circ}$ corresponds to a hydrophilic surface. Vogler [13] sets the limit at $65^{\circ}$. In this case, the values of the water contact angles are lower than $50^{\circ}$, so cells can be considered hydrophilic. The values of Table 2 were used to calculate cell surface tension parameters (Table 3 ). Table 3 also presents the values of the degree

Table 1

Number of cells of C. albicans 12A, C. albicans 46B, C. dubliniensis 7987 and C. dubliniensis 7988 adhered to acrylic and hydroxyapatite (HAP) in the presence of water and artificial saliva

\begin{tabular}{|c|c|c|c|c|}
\hline \multirow[t]{3}{*}{ Strain } & \multicolumn{4}{|c|}{ Mean number of yeasts $/ \mathrm{mm}^{2}\left( \pm \mathrm{SEM}^{\mathrm{a}}\right)$} \\
\hline & \multicolumn{2}{|l|}{ Water } & \multicolumn{2}{|l|}{ Artificial saliva } \\
\hline & Acrylic & HAP & Acrylic & HAP \\
\hline C. albicans $12 \mathrm{~A}$ & $4958 \pm 887$ & $18746 \pm 6891$ & $17916 \pm 4492$ & $15385 \pm 1820$ \\
\hline C. albicans 46B & $8071 \pm 3021$ & $15903 \pm 6669$ & $16209 \pm 1280$ & $18894 \pm 2958$ \\
\hline C. dubliniensis 7987 & $6628 \pm 2444$ & $15887 \pm 2018$ & $14333 \pm 644$ & $18531 \pm 2532$ \\
\hline C. dubliniensis 7988 & $6342 \pm 1875$ & $12836 \pm 3967$ & $15065 \pm 3130$ & $19107 \pm 3509$ \\
\hline
\end{tabular}

${ }^{a}$ SEM: standard error of mean. 


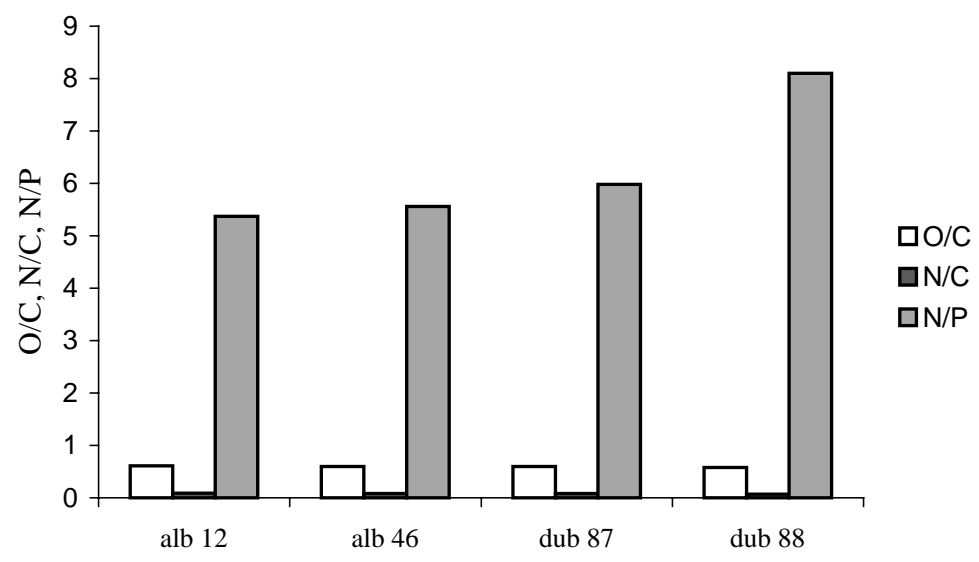

Fig. 1. Ratios of O/C, N/C and N/P of cell walls of C. albicans 12A (alb 12), C. albicans 46B (alb 46), C. dubliniensis 7987 (dub 87) and C. dubliniensis 7988 (dub 88), obtained by XPS analysis.

Table 2

Values of contact angles measured with water $\left(\theta_{\mathrm{w}}\right)$, formamide $\left(\theta_{\mathrm{f}}\right)$ and 1-bromonaphatelene $\left(\theta_{\mathrm{b}}\right)$ on cells lawns of C. albicans 12A, C. albicans 46B, C. dubliniensis 7987 and C. dubliniensis 7988 conditioned with water or artificial saliva ${ }^{a}$

\begin{tabular}{llcll}
\hline Medium & Cells & $\theta_{\mathrm{w}}\left({ }^{\circ}\right)\left( \pm \mathrm{SEM}^{\mathrm{a}}\right)$ & $\theta_{\mathrm{f}}\left({ }^{\circ}\right)\left( \pm \mathrm{SEM}^{\mathrm{a}}\right)$ & $\theta_{\mathrm{b}}\left({ }^{\circ}\right)\left( \pm \mathrm{SEM}^{\mathrm{a}}\right)$ \\
\hline Water & C. albicans 12A & $6 \pm 5$ & $18 \pm 1$ & $65 \pm 5$ \\
& C. albicans 46B & $17 \pm 4$ & $19 \pm 3$ & $60 \pm 5$ \\
& C. dubliniensis 7987 & $24 \pm 2$ & $28 \pm 2$ & $44 \pm 3$ \\
& C. dubliniensis 7988 & $18 \pm 2$ & $18 \pm 2$ & $57 \pm 2$ \\
Artificial saliva & C. albicans 12A & $15 \pm 2$ & $16 \pm 1$ & $63 \pm 7$ \\
& C. albicans 46B & $13 \pm 1$ & $14 \pm 2$ & $63 \pm 1$ \\
& C. dubliniensis 7987 & $13 \pm 2$ & $12 \pm 2$ & $62 \pm 5$ \\
\hline
\end{tabular}

${ }^{a}$ SEM: standard error of mean.

of hydrophobicity of yeast cell surfaces $\left(\Delta G_{\mathrm{sws}}\right) . \Delta G_{\mathrm{sws}}$ is expresses the free energy of interaction between two identical surfaces (s) immersed in water (w), as proposed by van Oss and Giese [12]. $\Delta G_{\text {sws }}$ was determined with the values $\gamma^{+}, \gamma^{-}$(electron-acceptor and electron-donor parameters of acid-base component of the surface tension) and $\gamma^{\mathrm{LW}}$ (the Lifshitz van der Waals component of surface tension), which were calculated with the contact angles of water, formamide and 1-bromonaphtalene.
From Table 3, the four strains studied showed similar values of surface tension and a predominantly electron donancy. In the presence of artificial saliva a slightly increase in the electron-acceptor parameter $\left(\gamma^{+}\right)$was verified for all strains. As far as hydrophobicity is concerned, all Candida strains studied showed positive values of $\Delta G_{\text {sws }}$ in all conditions assayed, and so can be considered hydrophilic, which is in accordance with the water contact angle values. The $\Delta G_{\text {sws }}$ values were very similar, with the exception of $C$. albicans

Table 3

Values of the components of surface tension $\left(\gamma^{+}, \gamma^{-}, \gamma^{\mathrm{LW}}\right)$ and degree of hydrophobicity $\left(\Delta G_{\mathrm{sws}}\right)$ of cells (C. albicans 12A (alb 12), C. albicans 46B (alb 46), C. dubliniensis 7987 (dub 87) and C. dubliniensis 7988 (dub 88)) conditioned with water or artificial saliva and the average zeta potential of the yeast cells measured in water ${ }^{\mathrm{a}}$

\begin{tabular}{llllllr}
\hline Medium & Cells & $\begin{array}{l}\gamma^{+}\left(\mathrm{mJ} \mathrm{m}^{-2}\right) \\
\left( \pm \mathrm{SEM}^{\mathrm{a}}\right)\end{array}$ & $\begin{array}{l}\gamma^{-}\left(\mathrm{mJ} \mathrm{m}^{-2}\right) \\
\left( \pm \mathrm{SEM}^{\mathrm{a}}\right)\end{array}$ & $\begin{array}{l}\gamma^{\mathrm{LW}}\left(\mathrm{mJ} \mathrm{m}^{-2}\right) \\
\left( \pm \mathrm{SEM}^{\mathrm{a}}\right)\end{array}$ & \multicolumn{1}{c}{$\begin{array}{l}\Delta G_{\text {sws }}\left(\mathrm{mJ} \mathrm{m}^{-2}\right) \\
\left( \pm \mathrm{SEM}^{\mathrm{a}}\right)\end{array}$} & $\begin{array}{l}\zeta(\mathrm{mV}) \\
\left( \pm \mathrm{SEM}^{\mathrm{a}}\right)\end{array}$ \\
\hline Water & alb 12 & $5.04 \pm 1.46$ & $48.66 \pm 5.59$ & $23.43 \pm 23.13$ & $21 \pm 3$ & $-14.5 \pm 4.2$ \\
& alb 46 & $4.62 \pm 1.86$ & $51.22 \pm 2.21$ & $25.04 \pm 2.38$ & $24 \pm 4$ & $-8.3 \pm 3.3$ \\
& dub 87 & $3.03 \pm 1.31$ & $52.00 \pm 2.48$ & $29.98 \pm 1.42$ & $27 \pm 2$ & $-17.8 \pm 3.7$ \\
& dub 88 & $5.91 \pm 1.19$ & $49.12 \pm 2.39$ & $24.09 \pm 1.81$ & $20 \pm 3$ & - \\
Artificial saliva & alb 12 & $6.37 \pm 0.53$ & $51.60 \pm 1.26$ & $23.53 \pm 1.10$ & $21 \pm 4$ & - \\
& alb 46 & $13.2 \pm 0.64$ & $51.57 \pm 1.76$ & $13.61 \pm 0.35$ & $10 \pm 1$ & - \\
& dub 87 & $6.18 \pm 1.53$ & $52.17 \pm 0.42$ & $24.20 \pm 2.61$ & $22 \pm 2$ & - \\
& dub 88 & $6.02 \pm 1.74$ & $53.10 \pm 1.46$ & $24.61 \pm 2.96$ & $23 \pm 4$ & - \\
\hline
\end{tabular}

${ }^{\text {a }}$ SEM: standard error of mean. 
Table 4

Values of contact angles measured with water $\left(\theta_{\mathrm{w}}\right)$, formamide $\left(\theta_{\mathrm{f}}\right)$ and 1-bromonaphatelene $\left(\theta_{\mathrm{b}}\right)$ on acrylic and HAP coated with water or artificial saliva $^{\mathrm{a}}$

\begin{tabular}{lllll}
\hline Medium & Cells & $\begin{array}{l}\theta_{\mathrm{w}}\left(^{\circ}\right) \\
\left( \pm \mathrm{SEM}^{\mathrm{a}}\right)\end{array}$ & $\begin{array}{l}\theta_{\mathrm{f}}\left(^{\circ}\right) \\
\left( \pm \text { SEM }^{\mathrm{a}}\right)\end{array}$ & $\begin{array}{l}\theta_{\mathrm{b}}\left(^{\circ}\right) \\
\left( \pm \text { SEM }^{\mathrm{a}}\right)\end{array}$ \\
\hline Water & Acrylic & $75 \pm 3$ & $57 \pm 3$ & $32 \pm 9$ \\
& HAP & $53 \pm 4$ & $57 \pm 6$ & $47 \pm 3$ \\
Artificial saliva & Acrylic & $64 \pm 4$ & $44 \pm 3$ & $36 \pm 3$ \\
& HAP & $23 \pm 3$ & $25 \pm 83$ & $43 \pm 2$ \\
\hline
\end{tabular}

a SEM: standard error of mean.

46B, that exhibited a lower degree of hydrophilicity, in the presence of artificial saliva.

Table 3 also shows the values of zeta potentials of the four Candida strains when immersed in water. Under these conditions, they all displayed negative zeta potentials and the results did not differ statistically. When immersed in artificial saliva, all strains showed no electrophoretic mobility at 50, 100 and $200 \mathrm{mV}$, which was expected due to the high ionic strength of the medium. Thus, their zeta potentials were considered nulls.

\subsection{Materials surface properties}

As adhesion involves both cells and materials, the surface properties of the tested substrata were determined. Contact angle values are presented in Table 4, surface tension and hydrophobicity in Table 5 , surface elemental composition in Table 6 and roughness in Fig. 2.

The values of water contact angle (Table 4) indicate that HAP is more hydrophilic than acrylic, which can be considered hydrophobic. The water contact angle on the materials conditioned with artificial saliva decreases. Consequently, the $\Delta G_{\text {sws }}$ value of acrylic becomes less negative when coated with artificial saliva (less hydrophobic) whereas in the case of HAP artificial saliva decreased the $\Delta G_{\text {sws }}$ values (more hydrophilic) (Table 5). Table 5 also shows that the electron-donor parameter increased in the presence of artificial saliva for both materials. Although that increase is higher for acrylic, $\gamma^{-}$is always higher in HAP (Table 5).

The elemental analysis of acrylic and HAP surfaces conditioned with water or artificial saliva (Table 6) indicated that artificial saliva altered the surface composition of both materials with special relevance for HAP.

There was no difference between the data obtained by the longitudinal and the transversal measurements of roughness
Table 6

Percentage of the different chemical elements detected in the surface of acrylic and HAP, contacted with water or artificial saliva, determined by XPS analysis

\begin{tabular}{lccccc}
\hline Elements $(\%)$ & \multicolumn{2}{l}{ Acrylic } & & HAP \\
\cline { 2 - 3 } \cline { 6 - 6 } \cline { 6 - 6 } & Water & $\begin{array}{l}\text { Artificial } \\
\text { saliva }\end{array}$ & & Water & $\begin{array}{l}\text { Artificial } \\
\text { saliva }\end{array}$ \\
\hline C 1s & 75.75 & 72.80 & & 23.20 & 14.05 \\
O 1s & 22.48 & 23.11 & & 45.85 & 46.16 \\
N 1s & 0.76 & 1.02 & & 0.30 & 0.39 \\
P 2p & 0.04 & 0.32 & & 12.50 & 14.18 \\
Si 2p & 0.97 & 1.92 & & - & - \\
Na 1s & - & 0.83 & & - & 12.09 \\
Ca 2p $\left(2 p^{3}+2 p^{1}\right)$ & - & - & & 18.15 & 9.87 \\
K 2p $\left(2 p^{3}+2 p^{1}\right)$ & - & - & & - & 3.25 \\
\hline
\end{tabular}

for each type of material (Fig. 2). By the comparison of the roughness of HAP and acrylic, it could be concluded that the former exhibits a surface roughness about two times the latter.

\section{Discussion}

It is well known that cell surface hydrophobicity plays an important role in adhesion of Candida species. Hydrophobic cells bind more readily, to epithelial cells and plastics, than hydrophilic ones [14]. Both Candida albicans strains used in this study exhibited hydrophilic cell surfaces under the conditions assayed. The same was observed for the two strains of Candida dubliniensis. Moreover, there were no significant differences between $C$. albicans and C. dubliniensis hydrophobicity, either conditioned with water or artificial saliva (Table 3).

Other authors [15] found differences in the hydrophobicity of some strains of $C$. albicans and $C$. dubliniensis when grown at $37^{\circ} \mathrm{C}$. The results reported by these authors were based on the hydrophobic microspheres assay method. However, the drawback of this method and others like co-aggregation [16] and microbial adhesion to hydrocarbons [17], is that other forces (as electrostatic), besides hydrophobic ones, may interfere in the interaction between the ligands and the cell surface, and so, surface hydrophobicity is masked $[18,19]$. Furthermore, the fact that the results obtained in the present study are consistent across two strains of each Candida species strongly suggests that these results are not an artefact of chance strain selection.

Table 5

Values of surface tension components $\left(\gamma^{+}, \gamma^{-}, \gamma^{\mathrm{LW}}\right)$ and degree of hydrophobicity $\left(\Delta G_{\mathrm{sws}}\right)$ of acrylic and HAP conditioned with water or artificial saliva

\begin{tabular}{lllclr}
\hline & Surface & $\gamma^{+}\left(\mathrm{mJ} / \mathrm{m}^{2}\right)\left( \pm \mathrm{SEM}^{\mathrm{a}}\right)$ & $\gamma^{-}\left(\mathrm{mJ} / \mathrm{m}^{2}\right)\left( \pm \mathrm{SEM}^{\mathrm{a}}\right)$ & $\gamma^{\mathrm{LW}}\left(\mathrm{mJ} / \mathrm{m}^{2}\right)\left( \pm \mathrm{SEM}^{\mathrm{a}}\right)$ & $\Delta G_{\mathrm{sws}}\left(\mathrm{mJ} / \mathrm{m}^{2}\right)\left( \pm \mathrm{SEM}^{\mathrm{a}}\right)$ \\
\hline \multirow{2}{*}{ Water } & Acrylic & $0.91 \pm 0.09$ & $4.98 \pm 1.37$ & $39.77 \pm 3.00$ & $-45 \pm 0.2$ \\
& HAP & $0.05 \pm 0.00$ & $38.88 \pm 3.76$ & $31.37 \pm 1.82$ & $25 \pm 3.0$ \\
Artificial saliva & Acrylic & $0.68 \pm 0.10$ & $16.19 \pm 3.41$ & $35.84 \pm 1.36$ & $-26 \pm 4.0$ \\
& HAP & $1.16 \pm 0.53$ & $49.90 \pm 3.86$ & $33.37 \pm 0.89$ & $30 \pm 3.0$ \\
\hline
\end{tabular}

${ }^{\text {a }}$ SEM: standard error of mean. 


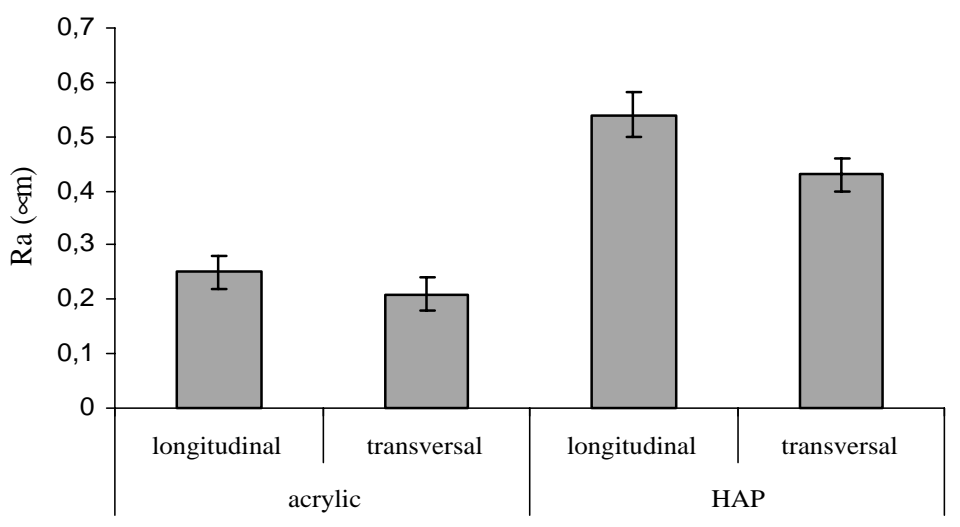

Fig. 2. Values of the roughness of acrylic and HAP measured in two different directions (longitudinal and transversal).

According to Rouxhet et al. [20], XPS analysis can provide an indication of the amount of polysaccharides, proteins and hydrocarbons present at the cell surface of yeast strains, which can be determined from the ratios $\mathrm{O} / \mathrm{C}, \mathrm{N} / \mathrm{C}$ and N/P. As all the strains present similar cell wall elemental compositions (Fig. 1), the polysaccharides, proteins and hydrocarbons contents are similar and in average the percentages are $66.0 \pm 1.0,27.9 \pm 3.0$ and $6.1 \pm 1.0$, respectively. These values are in accordance with the values reported by Chaffin et al. [21] for the cell wall composition of Candida albicans.

The XPS results corroborated the similarity of the values of the surface tension, hydrophobicity and zeta potential (Table 3), among all strains.

The liquid medium where adhesion took place strongly influenced the results. In the presence of artificial saliva, the number of cells adhered to acrylic, of the four strains studied, was significantly greater compared to water (Table 1). The environmental conditions, such as $\mathrm{pH}$, ionic strength, temperature and components in solution can influence cell surface characteristics [22], e.g. surface charge and hydrophobicity [23]. Moreover, ionic strength determines the thickness of the electrical double layer which has a direct influence on electrostatic interactions established in the adhesion events [24]. Thus, it is expected that artificial saliva, which has a high ionic strength, influences adhesion to oral surfaces, lowering the electrostatic repulsion. Furthermore, the adsorption of salivary components can also affect adhesion. It has been reported by several authors that adhesion of Candida albicans to oral surfaces is influenced by saliva [25-28]. Saliva can enhance the adhesion to acrylic surfaces [27] and polystyrene [28], whereas adhesion to silicone rubber can be discouraged in the presence of saliva [26]. This fact has been attributed to the adsorption of different salivary components, including mucins [29], other salivary proteins [30] and secretory IgA [28].

It must be stressed that the saliva formulation used in this study is a synthetic one without proteins. In almost all studies concerning adhesion of oral micro-organisms to surfaces, the saliva used is obtained from donors $[31,32]$. Nevertheless, natural saliva varies according to the donor and the time of the day, thus exact duplications are impossible. Furthermore, natural saliva contains proteins such as mucin that can coat the oral surfaces influencing adhesion by specific interactions. So, artificial saliva was used in this study, in order to focus only the physico-chemical interactions.

In the present study, the adsorption of phosphate ions to acrylic surfaces, indicated by XPS analysis (Table 6), caused an increase in the electron donancy of this material (Table 5). Moreover, the cells in the presence of artificial saliva exhibited a slightly increase in their electron-acceptor groups (Table 3). Thus, the increase in the number of adhered cells to acrylic in the presence of artificial saliva can be explained by an increase in the interactions between the electron-donor groups of acrylic and the electron-acceptor groups of cells. In the case of HAP, artificial saliva caused an increase in the number of electron-acceptor groups, perhaps due to the adsorption of sodium and potassium ions, as observed by XPS analysis (Table 6). Probably, in opposition to acrylic, there was no such significant increase in the interactions between the electron-acceptor groups of cells and electron-donating groups of HAP, which can explain the similarity in the number of adhered cells.

The preferential adsorption of phosphate to acrylic and sodium and potassium to HAP can be explained by the fact that acrylic is more electron accepting than HAP and that HAP is more electron donating than acrylic. It has been suggested by other authors [26] that the different behaviours of cell attachment in the presence of artificial saliva may be related to the hydrophobicity of the substratum surfaces which may stimulate the adsorption of different salivary components, a proposal which is true for the present study.

It is curious to notice that the number of cells attached to HAP was greater than to acrylic in the presence of water, although HAP is less hydrophobic than acrylic. Furthermore, the adhesion to acrylic increased in the presence of artificial saliva and in this medium acrylic was less hydrophobic. This indicates that the hydrophobicity of the adhesion substratum played a minor role in the process of adhesion. So it is expected that other types of interactions rather than hydrophobic ones might be governing the phenomenon. 
The interactions established between the electron-acceptor groups of the cells and the electron-donating groups of the materials, as hypothesised before, may be determining the adhesion phenomenon.

Studies done by Bollen et al. [33] showed that an increase in the surface roughness of resin strips above an Ra value of $2 \mu \mathrm{m}$ resulted in a dramatic increase in bacterial colonisation of these surfaces in comparison to smooth strips $(\mathrm{Ra}=0.12 \mu \mathrm{m})$. Verran and Maryan [34] demonstrated that surface roughness may also facilitate Candida albicans retention in silicon prostheses. Taylor et al. [35] verified that an increase in surface roughness $(0.15-3.53 \mu \mathrm{m})$ enhanced Candida albicans retention. Although the values of roughness of both materials are low $(\mathrm{Ra}<0.5 \mu \mathrm{m})$ the roughness of HAP is higher than that of acrylic (Fig. 2), which can, in part, explain the higher amount of cells adhered to HAP in the absence of artificial saliva. When artificial saliva was present this effect might have been masked.

It should be noted that the acrylic used in the present work was a cold-cure variety of acrylic. However, most dentures are made of a heat-cured acrylic form of resin. Nevertheless, according to Davenport [36] there is no difference in surface roughness between the heat and cold-cure acrylic resin. So, it is expected that they have similar surface properties as they are made by the same chemical compounds.

As the different Candida strains showed similar cell wall compositions and cell surface physico-chemical properties they were expected to exhibit the same type of physico-chemical interaction with the adhesion substratum. Accordingly, all strains studied exhibited the same capability to adhere to both types of surfaces. These results proved the similarity of the phenotypic characteristics of Candida albicans and Candida dubliniensis, with respect to physico-chemical surface properties. The extent of adhesion of Candida strains to teeth (HAP) and prostheses (acrylic) is similar in the presence of artificial saliva, which may indicate that both surfaces are equally important reservoirs for candidal infections.

\section{Acknowledgements}

The authors fully acknowledge the financial support of FCT/Portugal through the grant BD3195/2000 and the project POCTI/BIO/42638/2001. We kindly thank the following Departments of the University of Porto: Metallurgic and Materials Engineering (Dr. José Domingos dos Santos and Dr. Ascensão Lopes), for HAP disks; Chemical Engineering (Prof. Luís de Melo), for contact angle measurements and Biomedical Engineering Institute (Dr. Fernando Jorge Monteiro), for roughness measurements. We also would like to thank the Department of Biology (Dr. Célia Pais and Dr. Judite Almeida) of the University of Minho, for providing the Candida albicans strains.

\section{References}

[1] J. Pla, C. Gil, L. Monteoliva, F. Navarro-García, M. Sanchez, C. Nombela, Yeast 12 (1996) 1677.

[2] R.D. Cannon, W. L, Crit. Rev. Oral Biol. Med. 10 (1999) 359.

[3] R.A. Calderone, W.A. Fonzi, Trends Microbiol. 9 (2001) 327.

[4] D.J. Sullivan, T.J. Westerneng, K.A. Haynes, D.E. Bennett, D.C. Coleman, Microbiology 141 (1995) 1507.

[5] G.P. Moran, D. Sanglard, S.M. Donnelly, D.B. Shanley, D.J. Sullivan, D.C. Coleman, Agents Chemother. 42 (1998) 1819.

[6] G.D. Gilfillan, D.J. Sullivan, K. Haynes, T. Parkinson, D.C. Coleman, N.A.R. Gow, Microbiology 144 (1998) 829.

[7] L.P. Samaranayke, T. W, Arch. Oral Biol. 25 (1980) 603.

[8] J.C. Davenport, Br. Dental J. 129 (1970) 151.

[9] J. Gal, Y. Fovet, M. Adib-Yadzi, Talanta 53 (2001) 1103.

[10] M.A. Lopes, J.C. Knowles, J.D. Santos, F.J. Monteiro, I. Olsen, Biomaterials 21 (2000) 1165.

[11] M. Henriques, K. Gasparetto, J. Azeredo, R. Oliveira, Biotechnol. Lett. 24 (2002) 1111.

[12] C.J. van Oss, R.F. Giese, Clay Miner. 2 (1995) 347.

[13] E.A. Vogler, Adv. Colloid Interf. Sci. 74 (1998) 69.

[14] J. Masuoka, G. Wu, P.M. Glee, K.C. Hazen, FEMS Immunol. Med. Microbiol. 24 (1999) 421.

[15] K.C. Hazen, J.G. Wu, J. Masuoka, Infect. Immun. 69 (2001) 779 .

[16] M.A. Jabra-Rizk, W.A. Falkler Jr., W.G. Merz, J.I. Kelley, A.A.M.A. Baqui, T.F. Meiller, J. Clin. Microbiol. 37 (1999) 1464.

[17] Y.H. Samaranayke, P.C. Wu, L.P. Samaranayke, M. So, APMIS 103 (1995) 707.

[18] R.J. Doyle, Microbes Infect. 2 (2000) 391.

[19] M. Aguedo, Y. Waché, V. Mazonyer, A. Sequeira-Le Grand, J. Belin, J. Agric. Food Chem. 51 (2003) 3007.

[20] P.G. Rouxhet, N. Mozes, P.B. Dengis, Y.F. Dufrêne, P.A. Gerin, M.J. Genet, Colloids Surf. B: Biointerf. 2 (1994) 347.

[21] W.L. Chaffin, J.L. López-Ribot, M. Casanova, D. Gozalbo, J.P. Martinez, Microbiol. Mol. Biol. Revi. 62 (1998) 130.

[22] M. Flahaut, D. Sanglard, M. Monod, J. Bille, M. Rossier, J. Clin. Microbiol. 36 (1998) 395.

[23] B. Hsu, C. Huang, Colloids Surf. A: Physicochem. Eng. Aspects 201 (2002) 201.

[24] R. Oliveira, Exp. Therm. Fluid Sci. 14 (1997) 316.

[25] J.M. O'Sullivan, H.F. Jenkinson, R.D. Cannon, Microbiology 146 (2000) 41

[26] H.J. Busscher, G.I. Geertsema-Doornbusch, H.C. van der Mei, J. Biomed. Mater. Res. 34 (1997) 201.

[27] K.W. Millsap, R. Bos, H.C. van der Mei, H.J. Busscher, Antonie van Leeuwenhoek 75 (1999) 351.

[28] R. San Millan, N. Elguezabal, P. Regulez, M.D. Moragues, G. Quindos, J. Ponton, Microbiology 146 (2000) 2105.

[29] M. Edgerton, F.A. Scannapieco, M.S. Reddy, M.J. Levine, Infect. Immun. 61 (1993) 2644.

[30] R.D. Cannon, A.K. Nand, H.F. Jenkinson, Microbiology 141 (1995) 213.

[31] E. Ueta, T. Tanida, S. Doi, T. Osaki, J. Lab. Clin. Med. 136 (2000) 67.

[32] H. Nikawa, J. Chen, T. Hamada, M. Nishimura, G. Polyzois, J. Oral Rehabil. 28 (2001) 526.

[33] C.M.L. Bollen, P. Lambrechts, M. Quirynen, Dental Mater. 13 (1997) 258.

[34] J. Verran, C.J. Maryan, J. Prosth. Dentistry 77 (1997) 535.

[35] R. Taylor, C. Maryan, J. Verran, J. Prosth. Dentistry 80 (1998) 592.

[36] J.C. Davenport, Br. Dental J. 133 (1972) 101. 